\title{
CLINICAL STUDY OF HYPERTENSIVE EMERGENCIES IN RURAL HOSPITAL
}

Srinivas $\mathrm{K}^{1}$, Praveen $\mathrm{N}^{2}$

\section{HOW TO CITE THIS ARTICLE:}

Srinivas K, Praveen N. "Clinical Study of Hypertensive Emergencies in Rural Hospital". Journal of Evolution of Medical and Dental Sciences 2014; Vol. 3, Issue 22, June 02; Page: 5979-5992,

DOI: $10.14260 /$ jemds/2014/2693

ABSTRACT: BACKGROUND AND OBJECTIVES: The clinical profile of patients with hypertensive emergencies presenting to rural hospitals in a developing country like ours is unknown. The objective of the present study was to evaluate the modes of presentations, clinical profile and spectrum of target organ damage in patients with hypertensive emergencies. METHOD: This observational study was done at SRI ADICHUNCHANGIRI INSTITUTE OF MEDICAL SCIENCES AND REASEARCH CENTER over a period of one and a half years. The study population included patients admitted to this hospital with severely elevated blood pressure with clinical or laboratory evidence of acute target organ damage. The clinical and laboratory profile of 50 patients were evaluated. RESULTS: Males had higher chances of developing a hypertensive emergency compared to females, male: female ratio 2.57:1. The commonest presenting symptoms were neurological deficit (50\%), dyspnea (30\%), followed by chest pain (24\%). Majority of the patients were known hypertensive (70\%). Higher levels of blood pressure at presentation were associated with an adverse outcome. Laboratory abnormalities noticed in these patients included hyponatremia and hyperkalemia. Acute intracerebral hemorrhage was the commonest mode of target organ damage. An in hospital mortality of $24 \%$ was observed in the present study.

INTRODUCTION: Hypertension affects individuals of all classes and across all age groups. The prevalence of hypertension increases with advancing age to the point where more than half of people of 60-69 years of age and approximately three-fourths of those 70 years of age and older are affected. ${ }^{1}$ The age related rise in SBP is primarily responsible for an increase in both incidence and prevalence of hypertension with increasing age. ${ }^{1}$ The relationship between blood pressure and risk of cardiovascular disease events is continuous, consistent and independent of other risk factors. ${ }^{1}$

Hypertension affects approximately one billion individuals worldwide as per the observations made by the Joint national committee on prevention, detection, evaluation and treatment of high blood pressure (JNC VII) report in 2003. ${ }^{1}$

Higher than optimal blood pressure is the number one attributable risk for death throughout the world and approximately 7.1 million deaths per year are attributed to uncontrolled hypertension. ${ }^{2}$

Target organ damage resulting from hypertension includes those affecting the brain, heart, kidneys and the eyes. A number of cardiovascular, pulmonary and neurological symptoms are found to be associated with patients in hypertensive emergency with target organ involvement. ${ }^{3}$ Focal neurological deficits, dyspnea, chest pain, headache, loss of vision, are considered as the commonest symptoms with which patients in hypertension related acute target organ damage present. ${ }^{3}$

As population ages the prevalence of hypertension will increase even further unless broad and effective preventive measures are implemented. ${ }^{1}$ 


\section{ORIGINAL ARTICLE}

Data from Framingham heart study suggests that individuals who are normotensive at 55 yrs. have a $90 \%$ lifetime risk for developing hypertension. ${ }^{4}$

Hypertensive emergency can be an end result of chronic hypertension, noncompliance to drugs, or new presentation of unrecognized essential hypertension. A hypertensive emergency is characterized by rapid deterioration of target-organs and poses an immediate threat to life. These conditions were invariable fatal before the advent of antihypertensive drugs. ${ }^{5}$

Hypertension is a major contributor to cardiovascular morbidity and mortality in India and worldwide. In India, one out of every five has hypertension and 50\% of people above 50yrs have hypertension. Hypertension is directly responsible for $57 \%$ of all stroke deaths and $24 \%$ of all coronary heart disease deaths in India. ${ }^{6}$ Epidemiological studies show that hypertension is present in $25 \%$ urban and $10 \%$ of rural subjects in India ${ }^{7}$. It is estimated that there are up to 31.5 million have hypertension in rural population. ${ }^{8}$

This clinical study of hypertensive emergencies is done in order to recognize this condition as early as possible, so as to reduce burden associated with it in terms of morbidity and mortality of our society.

\section{OBJECTIVES OF THE STUDY:}

1. To study the profile and modes of presentations of hypertensive emergencies in rural area.

2. To study the spectrum of end organ damage in hypertensive emergencies.

METHODOLOGY: This study was done on rural patients with hypertensive emergencies admitted to ICCU and ICU in Adichunchanagiri Institute of Medical Sciences and Research Centre a rural hospital situated in Bellur, Nagamangala Taluk, Mandya district from November 2010 to April 2012 (50 patients).On admission, detailed history was taken and a complete clinical examination was done. Patients with an elevated systolic blood pressure of $\geq 180 \mathrm{mmhg}$ or diastolic blood pressure of $\geq$ $120 \mathrm{mmhg}$, with history suggestive of acute target organ damage or with laboratory evidence of target organ damage were included in the study.

Statistical Methods: The data obtained was analyzed by descriptive statistics by means of percentage, proportions and depicted via bar charts, pie charts.

Type of Study: Observational study.

\section{SELECTION OF SUBJECTS: INCLUSION CRITERIA:}

1. Systolic blood pressure of $180 \mathrm{mmhg}$ and above or diastolic blood pressure of $120 \mathrm{mmhg}$ and above.

2. Evidence of end organ damage, either clinically or laboratory findings

\section{EXCLUSION CRITERIA:}

1. Patients less than 18 yrs. of age.

2. Chronic renal failure, valvular heart diseases, pregnancy induced hypertension (PIH). 


\section{ORIGINAL ARTICLE}

Diagnostic Criteria: The diagnosis of hypertensive emergency will be established by the following:

1. Systolic blood pressure $\geq 180 \mathrm{mmhg}$ or diastolic blood pressure $\geq 120 \mathrm{mmhg}$.

2. Acute target organ damage.

ACUTE TARGET ORGAN DAMAGE MAY INCLUDE: Hypertensive encephalopathy, intracerebral hemorrhage, subarachnoid hemorrhage, atherothrombotic brain infarction, acute left ventricular failure, acute myocardial infarction, unstable angina, acute aortic dissection, acute glomerulonephritis and papilledema.

\section{RESULTS:}

SEX DISTRIBUTION: Among the fifty subjects in the present study, 36 (72\%) were males and 14 were: females $(28 \%)$.

Male: female ratio 2.57:1

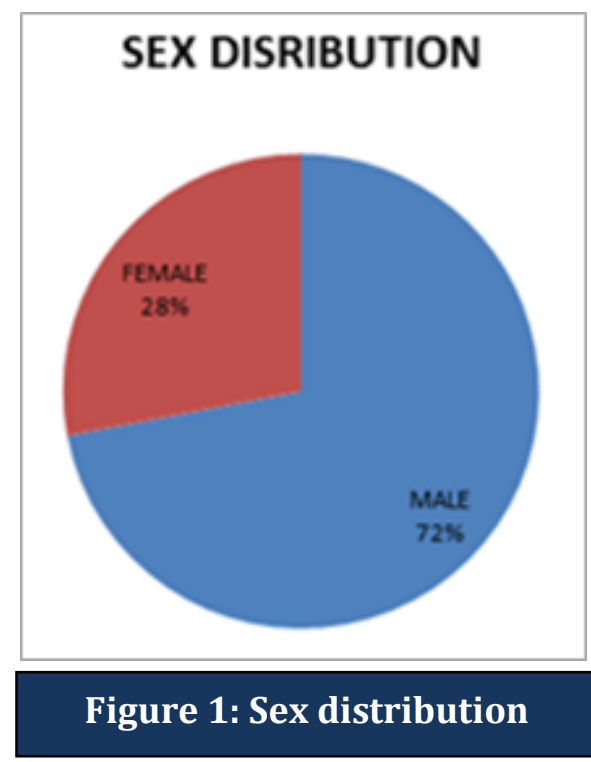

\section{AGE DISTRIBUTION:}

The mean age in patients was 60.38 years.

The age varied from 35 to 80 years in males and 56 to 77 years in females.

The mean age for male and female was 59.4 years and 62.7 years respectively.

\begin{tabular}{|c|c|c|}
\hline Age - Years & Frequency (N=50) & Percentage \\
\hline $30-39$ & 3 & $6 \%$ \\
\hline $40-49$ & 6 & $12 \%$ \\
\hline $50-59$ & 14 & $28 \%$ \\
\hline $60-69$ & 18 & $36 \%$ \\
\hline 70 years and more & 9 & $18 \%$ \\
\hline \multicolumn{2}{|c|}{ Table 1: Age distribution } \\
\hline
\end{tabular}




\section{ORIGINAL ARTICLE}

PRESENTING SYMPTOMS: In the present study the presenting symptoms in these patients were neurological deficits including convulsions, visual deficits, and cardiac symptoms like chest pain and dyspnea. The commonest presenting complaints were neurological deficits in 25 patients (50\%) followed by dyspnea in 15 (30\%) and chest pain in 12 patients $(24 \%)$.

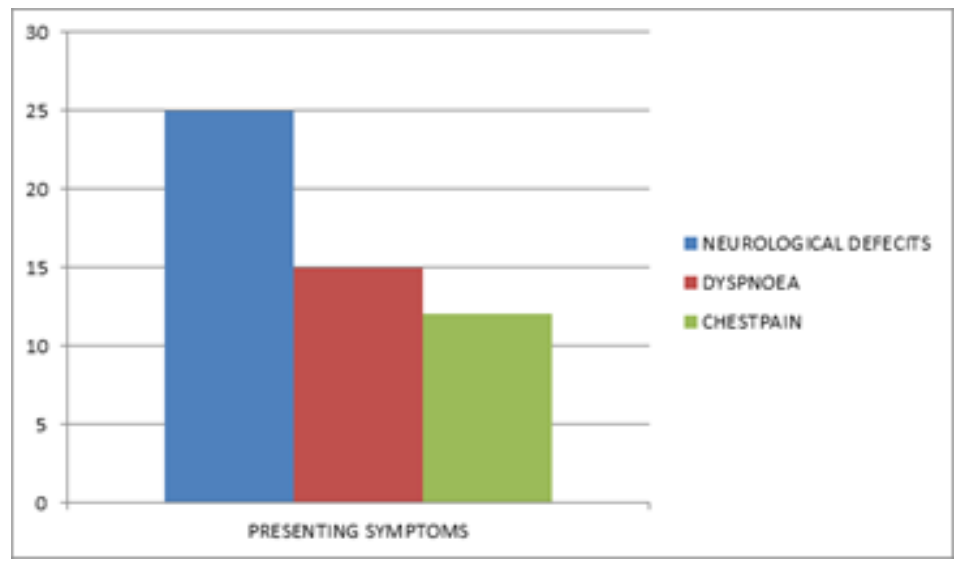

Figure 2: Presenting symptoms

NEUROLOGICAL DEFECITS: Among patients with neurological deficit, 20 patients (80\%) had hemiparesis, 3 patients (12\%) had convulsions and 2 patients (8\%) had visual disturbance, 16 patients Out of 25 patients who presented with neurological deficits were in altered sensorium.

\begin{tabular}{|c|c|c|}
\hline & Frequency $\mathbf{n = 2 5}$ & Percentage \\
\hline Hemiparesis & 20 & $80 \%$ \\
\hline Convulsions & 3 & $12 \%$ \\
\hline Visual deficit & 2 & $8 \%$ \\
\hline \multicolumn{2}{|c|}{ Table 2: Neurological deficits } \\
\hline
\end{tabular}

HYPERTENSIVE STATUS: Among the fifty patients studied 35 patients (70\%) were previously known hypertensive. This is represented in the figure 3 , below.

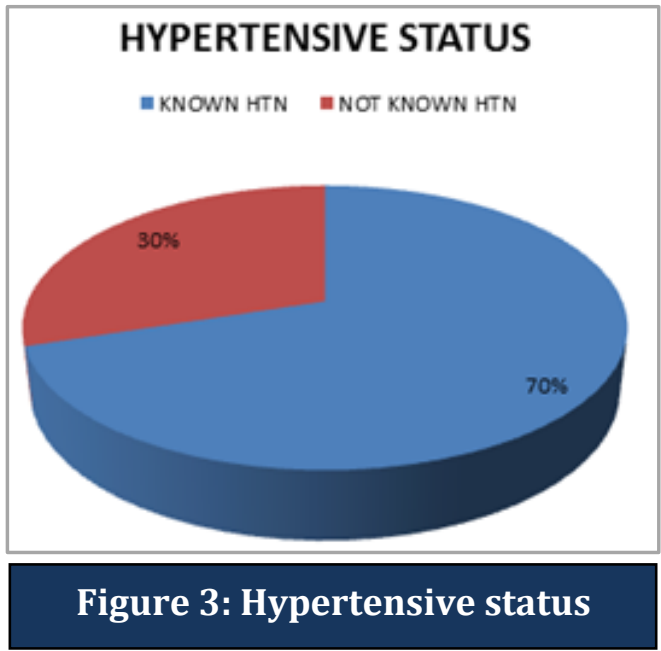




\section{ORIGINAL ARTICLE}

COMPLIANCE TO ANTIHYPERTENSIVE DRUGS: Out of the known hypertensive, 26 (74\%) were still continuing their antihypertensive medications while 9 patients (26\%) had discontinued medications.

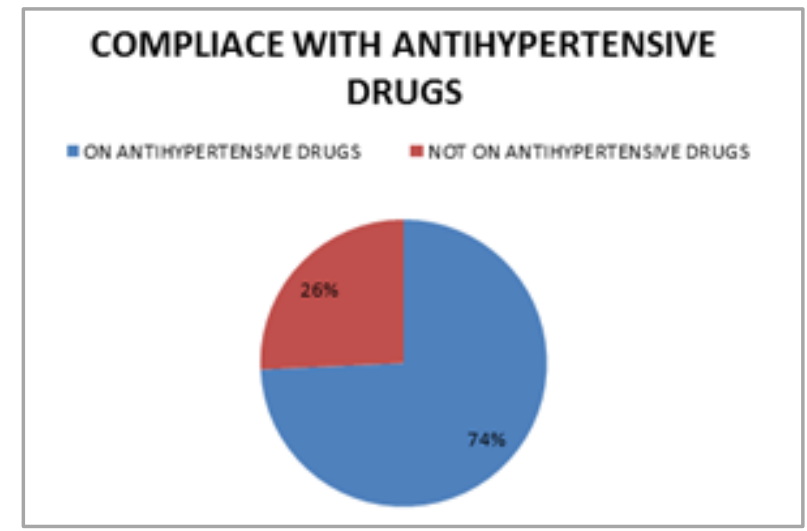

Figure 4: Compliance to antihypertensive medications

DIABETES AND DYSLIPIDEMIA: Of the 50 patients studied 15 patients (30\%) had diabetes mellitus and 20 patients ( $40 \%$ ) had dyslipidemia.

\begin{tabular}{|c|c|c|}
\hline & Frequency (n=50) & Percentage \\
\hline Diabetes mellitus & 15 & 30 \\
\hline Dyslipidemia & 20 & 40 \\
\hline
\end{tabular}

Table 3: Patients with diabetes mellitus and dyslipidemia

BLOOD PRESSURE MEASUREMENTS: Blood pressure measurements at the time of presentation, after one hour, at 24 hours and at the time of discharge are given below.

\section{SYSTOLIC BLOOD PRESSURE:}

\begin{tabular}{|c|c|c|c|}
\hline Systolic blood pressure mm hg & N & Mean deviation & Std \\
\hline AT ADMISSION & 50 & 216 & 24.74 \\
\hline AT ONE HOUR & 50 & 197 & 22.20 \\
\hline AT 24 HOURS & 50 & 163 & 22.01 \\
\hline AT DISCHARGE & 38 & 136 & 10.81 \\
\hline \multicolumn{2}{|c|}{ Table 4: Blood pressure measurements } \\
\hline
\end{tabular}

\section{DIASTOLIC BLOOD PRESSURE:}

\begin{tabular}{|c|c|c|c|}
\hline DIASTOLIC BLOOD PRESSURE mm hg & N & Mean & Std deviation \\
\hline AT ADMISSION & 50 & 125 & 18.41 \\
\hline AT ONE HOUR & 50 & 111 & 22.29 \\
\hline AT 24 HOURS & 50 & 96 & 10.99 \\
\hline AT DISCHARGE & 38 & 85 & 5.08 \\
\hline \multicolumn{5}{|c|}{ Table 5: Blood pressure measurements }
\end{tabular}




\section{ORIGINAL ARTICLE}

VARIATIONS IN BLOOD PRESSURE: Mean variation in blood pressure at one, 24 hours and at the time of discharge are given in the table below.

\begin{tabular}{|c|c|c|c|c|}
\hline SYSTOLIC BLOOD PRESSURE mm Hg & MEAN & Std DEVIATION & t & p \\
\hline SBP 0hrs- 1 hour & 19 & 20.65 & 6.47 & 0.001 VHS \\
\hline SBP 0hrs- 24 hours & 53 & 27.24 & 13.70 & 0.001 VHS \\
\hline SBP 0hrs- Discharge & 76 & 24.70 & 19.33 & 0.001 VHS \\
\hline
\end{tabular}

Table 6: Variations in blood pressure

\begin{tabular}{|c|c|c|c|c|}
\hline DIASTOLIC BLOOD PRESSURE mm Hg & MEAN & Std DEVIATION & t & p \\
\hline DBP 0hr- 1hr & 14 & 19.23 & 5.24 & 0.001 VHS \\
\hline DBP 0hr- 24hrs & 30 & 18.51 & 11.32 & 0.001 VHS \\
\hline DBP 0hrs-discharge & 37 & 16.61 & 13.91 & $0.001 \mathrm{VHS}$ \\
\hline
\end{tabular}

Table 7: Variations in blood pressure

The mean blood pressure readings in patients who were discharged from the hospital were systolic blood pressure of $212 \mathrm{~mm} \mathrm{Hg}$ and diastolic blood pressure of $121 \mathrm{~mm} \mathrm{Hg}$. Similar readings in patients who expired were systolic blood pressure of $224 \mathrm{~mm} \mathrm{Hg}$ and diastolic blood pressure of 138 $\mathrm{mm} \mathrm{Hg}$ respectively. This is represented in table 9 below.

\begin{tabular}{|c|c|c|}
\hline & Mean systolic blood pressure -mm hg & Mean diastolic blood pressure -mmhg \\
\hline Discharged & 212 & 121 \\
\hline Expired & 224 & 138 \\
\hline \multicolumn{3}{|c|}{$\begin{array}{c}\text { Table 8: Blood pressure at presentation- Patients who were } \\
\text { discharged from the hospital and those who expired }\end{array}$} \\
\hline \multirow{2}{*}{}
\end{tabular}

FUNDOSCOPIC EXAMINATION: Fundoscopic examination was done in every patient and the results are as given below. Fundoscopic evaluation was normal in 17 patients (34\%) 9 had grade I changes (18\%), 13 had grade II changes (26\%), 5 patients had grade III changes (10\%), 3 of the patients had evidence of papilledema (6\%). Fundus could not be visualized in 3 patients (6\%).

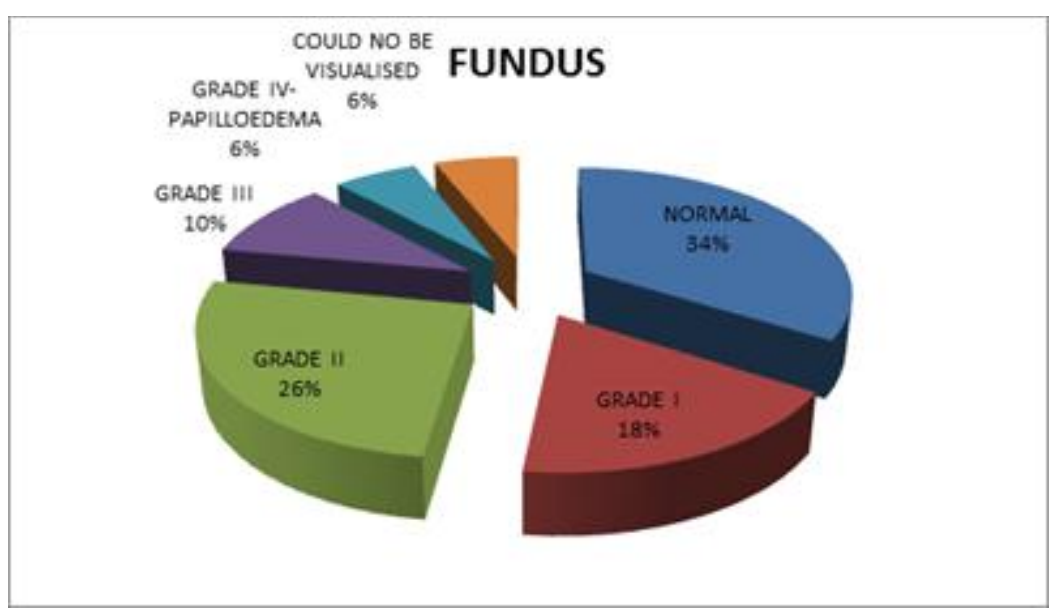

Figure 5: Fundoscopic examination 


\section{ORIGINAL ARTICLE}

ACUTE LEFT VENTRICULAR FAILURE: Out of 50 patients, 15 (30\%) patients had acute left ventricular failure.

\begin{tabular}{|c|c|c|}
\hline & Frequency $\mathbf{( N = 5 0 )}$ & Percentage \\
\hline Left ventricular failure & 15 & 30 \\
\hline No left ventricular failure & 35 & 70 \\
\hline \multicolumn{2}{|c|}{ Table 9: Acute Left ventricular failure } \\
\hline
\end{tabular}

CHEST RADIOGRAPH: Chest radiograph was suggestive of cardiomegaly in 15 patients and 4 patients had signs of pulmonary edema. Chest radiograph was normal in 31 patients.

\begin{tabular}{|c|c|c|}
\hline & Frequency (N=50) & Percentage \\
\hline Cardiomegaly & 15 & 32 \\
\hline Pulmonary edema & 4 & 8 \\
\hline Normal & 31 & 60 \\
\hline \multicolumn{2}{|c|}{ Table 10: Chest radiograph } \\
\hline
\end{tabular}

ECG CHANGES: Out of 50 patients 26 patients (52\%) had ST segment or T wave abnormalities, 10 (20\%) had ECG with voltage criteria suggestive of LVH and 7 patients had both the changes.

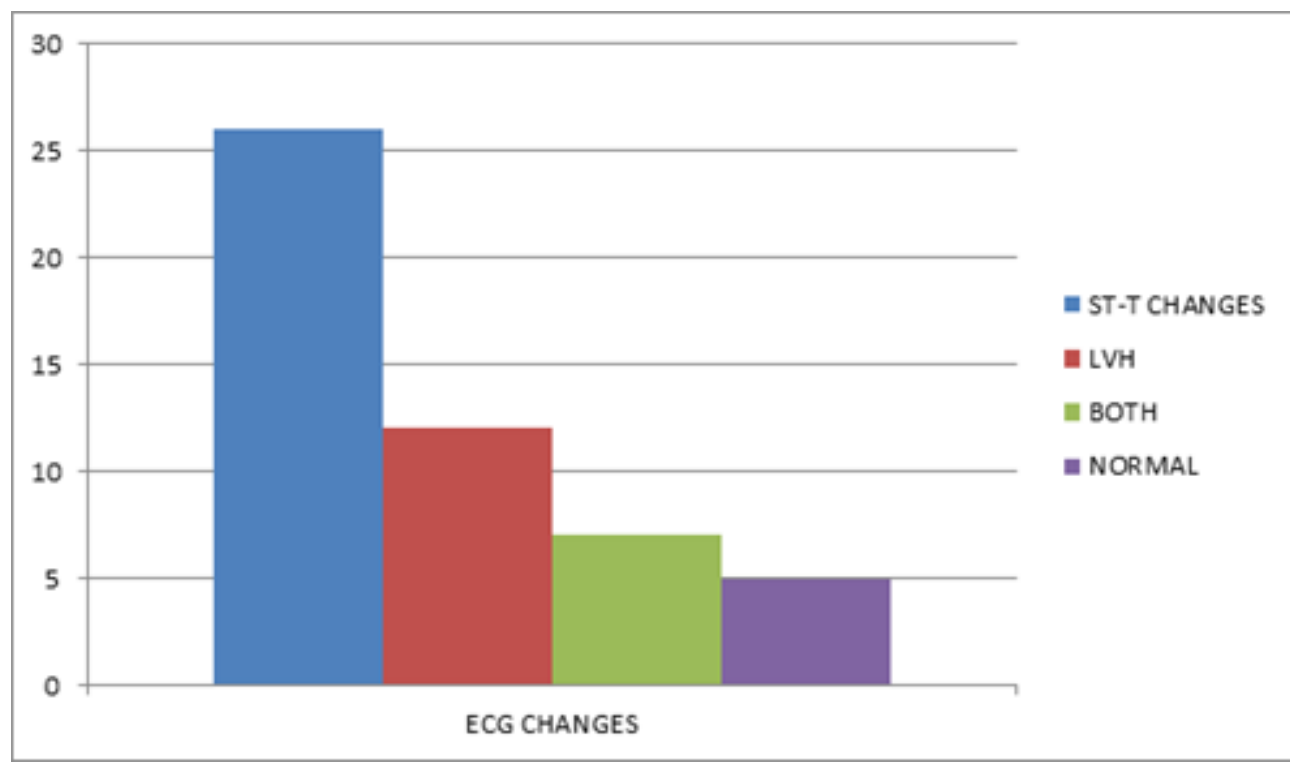

\section{Figure 6: ECG changes}

ECHOCARDIOGRAPHY: Echocardiography done in 25 patients with evidence of cardiac dysfunction showed left ventricular dysfunction in 13(52\%), regional wall motion abnormality in 8 patients (34\%), left ventricular hypertrophy in $6(26 \%)$ patients and normal echocardiographic study in 5 patients $(21 \%)$. 


\section{ORIGINAL ARTICLE}

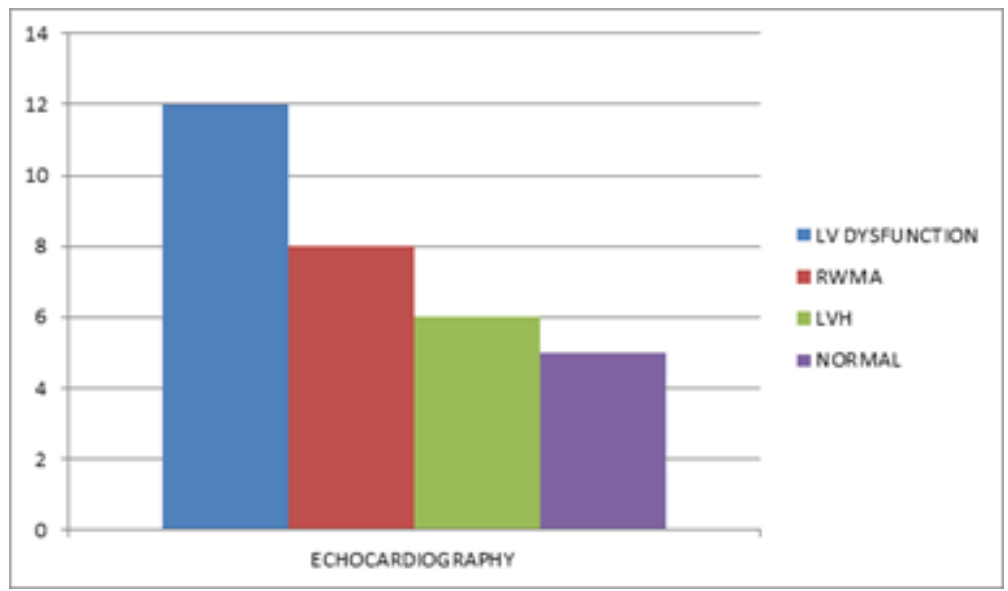

Figure 7: Echocardiography

RENAL FUNCTION TESTS: Serum urea was abnormal with levels above $40 \mathrm{mg} / \mathrm{dl}$ in 12 (24\%) of patients Serum creatinine level were above $1.4 \mathrm{mg} / \mathrm{dl}$ in $9(18 \%)$ of patients Serum urea and creatinine were elevated in 5 patients (10\%) and 7 patients out of 17 patients had elevated serum urea levels alone.

\begin{tabular}{|l|c|c|}
\hline & Frequency (N=50) & Percentage \\
\hline Elevated serum urea & 12 & 24 \\
\hline Elevated serum creatinine & 9 & 18 \\
\hline Elevated s.urea and s.creatinine & 5 & 10 \\
\hline \multicolumn{2}{|c|}{ Table 11: Renal Function tests }
\end{tabular}

RENAL SONOGRAM: Patients with laboratory evidence of renal dysfunction were subjected to renal sonogram. Out of 14 patients 5 patients had grade I changes, Two patients had grade II changes.

\begin{tabular}{|c|c|c|}
\hline Renal sonogram & Frequency(N=14) & Percentage \\
\hline Grade I & 5 & $29 \%$ \\
\hline Grade II & 2 & $11 \%$ \\
\hline \multicolumn{2}{|c|}{ Table 12: Renal sonogram } \\
\hline
\end{tabular}

ELECTROLYTE ABNORMALITIES: Hyponatremia with serum sodium levels less than $135 \mathrm{meq} / \mathrm{l}$ were seen in 15 patients (30\%) while 2 patients (4\%) had hypokalemia with serum potassium levels less than $3.5 \mathrm{meq} / \mathrm{l}$ and $4(8 \%)$ had hyperkalemia with potassium levels more than $5.0 \mathrm{meq} / \mathrm{l}$

\begin{tabular}{|c|c|c|}
\hline & Frequency (N=50) & Percentage \\
\hline Hyponatremia & 15 & 30 \\
\hline Hypokalemia & 6 & 12 \\
\hline Hyperkalemia & 4 & 8 \\
\hline \multicolumn{2}{|c|}{ Table 13: Electrolyte abnormalities } \\
\hline
\end{tabular}




\section{ORIGINAL ARTICLE}

MICROALBUMINURIA: Microalbuminuria was seen in 18 patients (36\%).

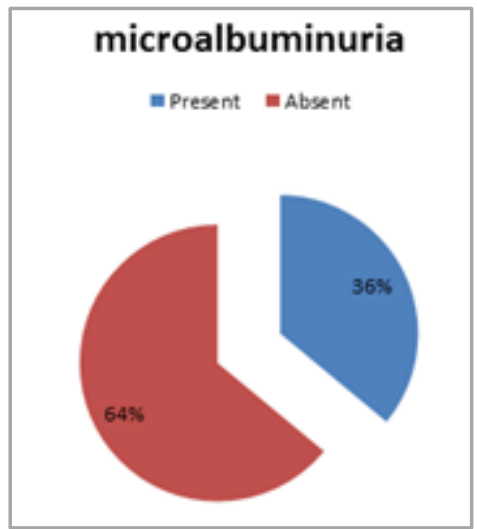

\section{Figure 8: Microalbuminuria}

COMPUTED TOMOGRAPHY: Neurological evaluation in symptomatic patients with computed tomography scan of brain revealed acute intracerebral hemorrhage in 15 patients, acute cerebral infarct in 6patients, subarachnoid hemorrhage was seen in 2 patients and normal study of the brain in 2 patients.

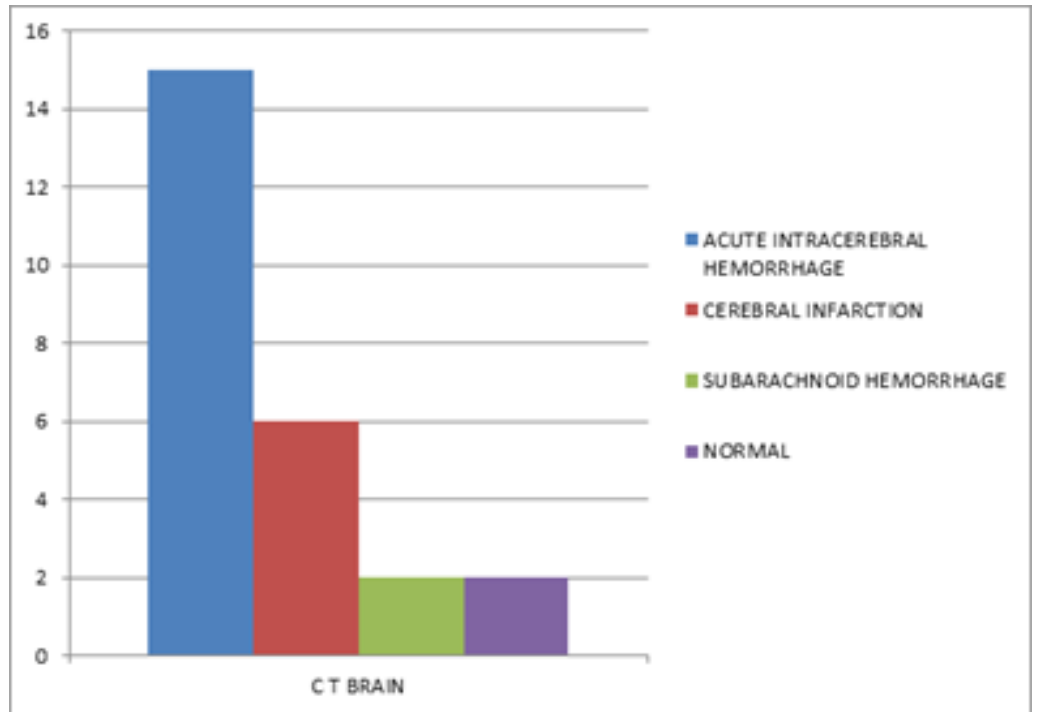

\section{Figure 9: Computed tomography of brain}

TARGET ORGAN DAMAGE: Neurological target organ damage included acute intracerebral hemorrhage 15 patients (30\%), subarachnoid hemorrhage in 2 patients (4\%), acute ischemic stroke 6 patients (12\%), hypertensive encephalopathy in 1 patient (2\%), cardiac target organ damage were acute left ventricular failure 14 patients (28\%), acute myocardial infarction in 2 patients (6\%), unstable angina in 7 patients (14\%), and malignant hypertension in 3 patient (6\%). 


\section{ORIGINAL ARTICLE}

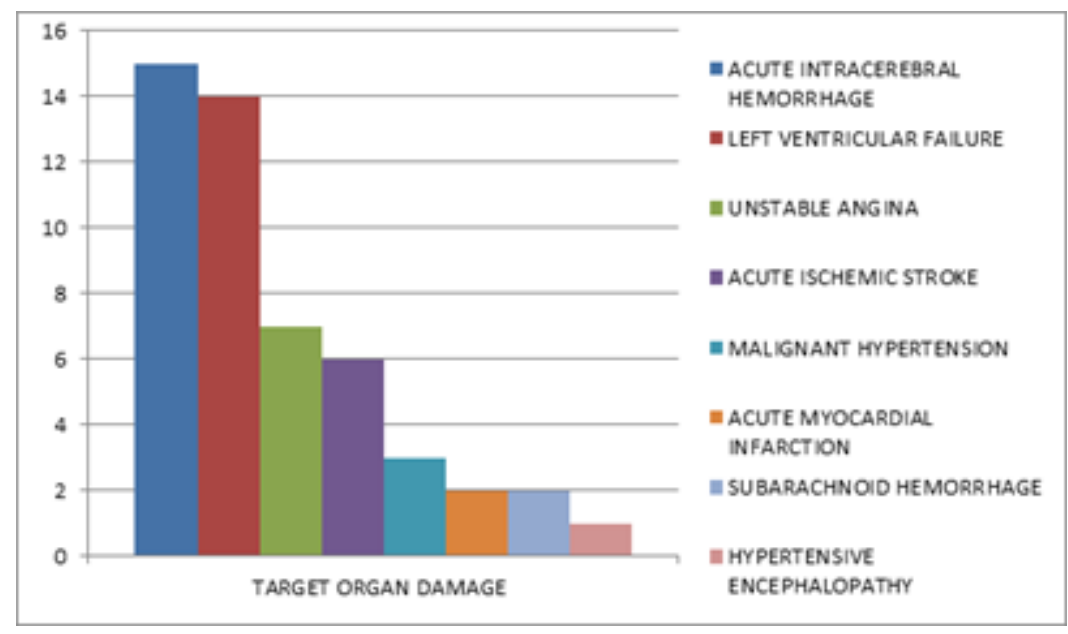

Figure 10: Target organ involvement

OUTCOME: Out of 50 patients with hypertensive emergencies, 12 patients died before discharge. Inhospital mortality was (24 percent).

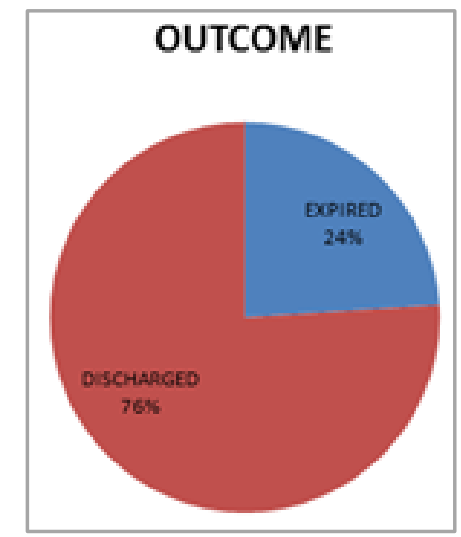

\section{Figure 11: Outcome}

\begin{tabular}{|l|c|c|}
\hline & DISCHARGED (N=38) & EXPIRED (N=12) \\
\hline MALE & 26 & 10 \\
\hline FEMALE & 12 & 2 \\
\hline MEAN AGE & $57.5 \mathrm{yrs}$ & $61.5 \mathrm{yrs}$ \\
\hline MEAN BP & $212 / 121 \mathrm{mmHg}$ & $224 / 138 \mathrm{mmHg}$ \\
\hline PRESENTING SYMPTOMS & & \\
\hline NEUROLOGICAL DEFECITS & 14 & 11 \\
\hline CHEST PAIN & 11 & 1 \\
\hline DYSPNOEA & 15 & - \\
\hline COMORBIDITIES & & 8 \\
\hline DIABETES & 7 & 5 \\
\hline DYSLIPIDEMIA & 15 & \\
\hline
\end{tabular}

Table 14: Characteristics of those discharged and expired 


\section{ORIGINAL ARTICLE}

DISCUSSION: In the present clinical study of hypertensive emergencies done at Adichunchangiri Institute of Medical Sciences and Research Centre the number of males presenting with hypertensive emergencies were more than the number of females.72\% of the patients were males.

Martin et al in their study on hypertensive crises observed that $55 \%$ of patients were males among patients with hypertensive emergencies. The proportions of males in hypertensive emergencies were also higher in the study by Zampaglione et al. This is probably due to an increased susceptibility of males compared with females to hypertension related target organ damage. This possibility is revealed in the Framingham study, which showed that the incidence of coronary arterial disease in men increased in an almost linear mode as age increased. ${ }^{9}$

The proportions of males were higher when studying the group of patients less than 50 years of age. Majority of female patients belonged to the postmenopausal age group which shows susceptibility of postmenopausal age to end organ damage. This is also due to the fact that postmenopausal female hemodynamics is not very much different from the male profile with regard to blood pressure..$^{10,11}$

Decade wise distribution of age shows largest groups belonging to the fifth and sixth decade at the time of presentation with $28 \%$ and $36 \%$ respectively.

Analyzing the presenting symptoms, the largest group of patients in the present study, presented with a neurological deficit (50\%), followed by dyspnea (30\%) and chest pain (24\%).

This was similar to the study by Martin et al, who in their study found presenting symptoms of neurological deficits, dyspnea and chest pain in 48\%, $25 \%$ and $18 \%$ of their patients.

Zampaglione et al in their study had more patients presenting with chest pain $(27 \%)$ followed by dyspnea (22\%) and neurological deficits (21\%).

Neurological deficits in the present study varied from hemiparesis (80\%), convulsions (12\%), and visual deficits (8\%). Hemiparesis accounted for the largest group of patients with neurological deficit.

Majority of patients in the present study were previously known hypertensive (70\%). Martin et al noticed a large number of patients, (83\%) in their study to be previously diagnosed hypertensive. Zampaglione et al reports a larger number, with (92\%) of known hypertensive among their patients.

This evidence confirms that hypertensive emergencies were higher in patients with previously known hypertension. This also shows that patients with hypertension are at a higher risk of developing a hypertensive emergency, more so if they do not adhere to the antihypertensive therapy.

In the present study $26 \%$ among the known hypertensive ignored their hypertensive status and discontinued antihypertensive medications which would have put them at a higher risk for acute target organ damage and hypertensive emergency.

Diabetes mellitus and dyslipidemia were the other risk factors present in the present group of patients. Patients with diabetes mellitus and dyslipidemia were $30 \%$ and $40 \%$ respectively in the present study. The number of patients with diabetes mellitus was $26 \%$ in the study done by martin et al.

These risk factors would have added to premature atherosclerosis and coronary artery disease in these patients predisposing them to acute target organ damage. 


\section{ORIGINAL ARTICLE}

Prevalence of arterial hypertension in diabetic patients is greater when compared with that in non-diabetic patients (40-50\% and 20\%, respectively). ${ }^{12}$

Metabolic abnormalities (hyperglycemia, hyperinsulinemia, and dyslipidemias) may play a role in the pathogenesis and complications of arterial hypertension, as seen in the present study.

Highest recorded systolic blood pressure was $280 \mathrm{~mm} \mathrm{Hg}$ with mean systolic blood pressure of $216 \pm 25 \mathrm{~mm} \mathrm{Hg}$. The highest diastolic blood pressure recorded was $180 \mathrm{mmhg}$ with a mean of 126 $\pm 18 \mathrm{~mm} \mathrm{Hg}$. Martin et al in their study reports a mean systolic blood pressure of $193 \pm 26 \mathrm{~mm} \mathrm{Hg}$ in their patients and a mean diastolic blood pressure of $129 \pm 12 \mathrm{~mm} \mathrm{Hg}$.

The mean reduction in blood pressure in one hour after admission to the hospital was $19 \mathrm{~mm}$ $\mathrm{Hg}$ of systolic blood pressure and $14 \mathrm{~mm} \mathrm{Hg}$ of diastolic blood pressure. Blood pressure levels at admission were higher in the group of patients who expired compared to those who were discharged from the hospital. The higher levels of blood pressure would have added to more severe target organ damage in these patients, with an adverse outcome.

This indicates worse prognosis with a higher levels of blood pressure at presentation.

Evaluation of fundus revealed changes ranging from hypertensive retinopathy to papilledema in 64 percent of patients. Papilledema was seen in $6 \%$ of patients which is an evidence of ongoing target organ damage in these patients.

Renal dysfunction in the form of raised serum urea and creatinine were seen in $24 \%$ and $18 \%$ of patients respectively. Renal ultrasonographic changes amounting to hypertensive target organ damage was seen in 7 patients.

Hyponatremia was observed in $30 \%$ of patients. $12 \%$ of the patients had hypokalemia compared to $8 \%$ with hyperkalemia reflecting secondary aldosteronism from increased renin secretion induced by intra renal ischemia.

Microalbuminuria was seen in $36 \%$ of the patients which puts these patients at a higher risk for hypertension related renal disease compared to the patients without proteinuria.

Computed tomography of the brain showed intracerebral hemorrhage as the commonest cause for the neurological target organ damage followed by cerebral infarct and subarachnoid hemorrhage.

Voltage criteria suggestive of left ventricular hypertrophy on ECG was seen in 10 patients $(20 \%)$.

Out of 25 patients who underwent echocardiography 6 patients (26\%) had left ventricular hypertrophy.

Evaluation for target organ damage in patients in the present study showed acute intracerebral hemorrhage in 30\% was the most common target organ damage, followed by including acute left ventricular failure in $28 \%$, and unstable angina in $14 \%$.

Study by Martin et al shows intracerebral hemorrhage (17\%) left ventricular failure (25 \%), acute ischemic stroke (39\%) and acute myocardial infarction in (8\%) their patients.

Zampaglione et al in their study observed target organ damage in the form of left ventricular failure (23\%), acute ischemic stroke (24\%) and intracerebral hemorrhage $(4.5 \%)$ in their patients.

The outcome of the study showed an in- hospital mortality of $24 \%$ among these patients.

In those who expired, males (20\%) were more than female (4\%), mean age was 61.5yrs, which was higher than those discharged $57.5 \mathrm{yrs}$, most of them presented with neurological deficits (91\%) and most them had diabetes and dyslipidemia. 


\section{ORIGINAL ARTICLE}

\section{CONCLUSION:}

- Majority of patients presenting in hypertensive emergency belonged to the fifth and sixth decades of age.

- Males have higher chances of developing hypertensive emergencies and higher mortality compared to females.

- Known hypertensives are at a higher risk of presenting with acute target organ damage associated with hypertensive emergency.

- Presence of diabetes mellitus and dyslipidemia increases the chance of developing hypertensive emergencies.

- Commonest mode of presentation is with a neurological deficit.

- Higher levels of blood pressure at presentation points towards a more adverse outcome.

- Hyponatremia and hypokalemia were common in patients with hypertensive emergencies.

- Acute intracerebral hemorrhage was the commonest form of target organ damage encountered in the present study.

- The in-hospital mortality among these patients with hypertensive emergency were 24 percent.

SUMMARY: The clinical profile of patients with hypertensive emergencies presenting to hospitals in a developing country like ours is poorly known.

The present study is a prospective observational study done at Adichunchangiri Institute of Medical Sciences and Research Centre, Bellur, Nagamangala over a period of one and a half years. The study population included patients admitted to this hospital with severely elevated blood pressure with clinical or laboratory evidence of acute target organ damage. The clinical and laboratory profile of 50 of these patients were evaluated. The commonest presenting symptoms were neurological deficit, dyspnea, chest pain followed by convulsions and loss of vision.

Majority of the patients were known hypertensive which was also seen in other similar studies and confirms that known hypertensive have a higher risk of developing hypertensive emergencies. Higher levels of blood pressure at presentation were associated with an adverse outcome. Acute intracerebral hemorrhage was the commonest target organ damage observed. An inhospital mortality of $24 \%$ was observed in the present study.

Hypertensive emergencies are common and can be devastating. Hence early diagnosis and treatment of hypertensive emergencies can reduce mortality and morbidity associated with.

In chronic hypertensive patients, strict blood pressure control by regular BP checkup and good adherence to antihypertensive drugs can reduce the incidence of hypertensive emergencies.

\section{BIBLIOGRAPHY:}

1. Joint national committee on prevention detection and treatment of high blood pressure. The seventh report of Joint national committee on prevention detection and treatment of high blood pressure. JAMA 2003; 289: 2560-2572.

2. World health report 2002: Reducing risks, promoting healthy life. Geneva, Switzerland, world health organization 2002

3. Karras et al. Lack of relationship between hypertension associated symptoms and blood pressure in hypertensive emergency department patients. American Journal of Emergency Medicine- vol 23(2) march 2005; 106-110 


\section{ORIGINAL ARTICLE}

4. Zampaglione et al. Hypertensive urgencies and emergencies. Hypertension1996; 27: 144-147

5. Ventura et al. Desperate disease, desperate measures: Tackling malignant hypertension in the 1950s. Am Heart J 2001; 142: 1970 203.

6. Gupta R. Trends in hypertension epidemiology in India. Journal of Human Hypertension 2004;18:73-78.

7. Waris M S. Needs for national hypertension control programme. Indian H J.1995.47; 409-10.

8. www.emedicine.com/med/topic1106.htm Sat Sharma, Claude Karkas hypertension/historical perspectives.

9. Elliot WJ. Hypertensive emergencies. In Critical Care Clinics Vol 17. Number 2 April 2001 W.B.Saunders company.

10. Messerli FH et al. Disparate cardiovascular findings in men and women with essential hypertension. Ann Intern Med 1987; 107: 158-61.

11. Owens JF et al. Menopausal status influences ambulatory blood pressure levels and blood pressure changes during mental stress. Circulation 1993; 88: 2794-802.

12. Sowers JR et al. Diabetes mellitus and associated hypertension, vascular disease, and nephropathy. An update. Hypertension 1995; 26: 869-79.

\section{AUTHORS:}

1. Srinivas K.

2. Praveen $\mathrm{N}$.

\section{PARTICULARS OF CONTRIBUTORS:}

1. Senior Resident, Department of Medicine, Mysore Medical College and Research Institute.

2. Assistant Professor, Department of Medicine, Adichunchangiri Institute of Medical Sciences \& Research Centre.

\section{NAME ADDRESS EMAIL ID OF THE}

\section{CORRESPONDING AUTHOR:}

Dr. Srinivas K,

\#4646, Shivaji Road,

N. R. Mohalla.

Mysore - 570007.

Email: drsrinivaskannaiah86@gmail.com

Date of Submission: 07/05/2014.

Date of Peer Review: 08/05/2014.

Date of Acceptance: 15/05/2014.

Date of Publishing: 28/05/2014. 